\title{
Migrating a professional field of study in a multi-institutional partnership: facilitators' experience in the competence-based curriculum development process
}

\author{
Proscovia Namubiru Ssentamu, Betty Akullu Ezati, Ronald Bisaso, \\ Elias Pekkola, and Seppo Hölttä*
}

\begin{abstract}
With the urge to Africanise the curriculum following colonisation, many African countries are still wary of the educational initiatives from the developed countries. However, with the clear curriculum design and development guidelines provided by various national Quality Assurance bodies, African countries need not fear migrating curricula from developed countries. Drawing from the workshop experiences, authors of this paper illustrate the steps involved in migrating, contextualising and adapting a professional field of study in a multi-institutional partnership, with particular focus on the competence-based curriculum design and development process. The process of migrating higher education (HE) Administration, Leadership and Management curriculum taught at the University of Tampere (Finland) to a Postgraduate Diploma in Higher Education Leadership and Management (PGDHELM) curriculum at Uganda Management Institute (UMI) in partnership with the Makerere University and the University of Helsinki involved undertaking a needs assessment, training of trainers and adapting the programme to the UMI context. The training of trainers provided opportunity for the trainees to reflect and generate information on the status of HE leadership and management in Uganda. The curriculum was institutionalised by aligning it to the vision, mission and profile of UMI in the context of the existing internal and external Quality Assurance frameworks. This paper underscores the importance of involving stakeholders, taking into account national and institutional requirements in all the steps when migrating an academic curriculum.
\end{abstract}

Keywords: competence-based curriculum; curriculum design; curriculum development; training programmes; quality assurance; partnership; internationalisation; infusion; higher education.

* The authors are grateful to all the partner institutions and staff who participated in the Leadership and Management of Ugandan Universities (LMUU1) Project "Strengthening Institutional Capacity for Higher Education Leadership and Management in Sub-Saharan Africa" and to the peer reviewers who gave insightful comments to improve on the quality of this article. 


\section{Introduction}

\section{Need for well-managed responsive universities}

Higher education (HE) is the heart of education, the core of national innovation and development systems, an instrument for poverty eradication and the accelerator of the rate of economic growth. ${ }^{1}$ Despite this documented contribution of HE to national development, the governance of HE in Uganda remains problematic. At the same time, training programmes addressing capacity needs in the governance of HE have either been nonexistent or have been developed in isolation from the expertise of various national and international higher education institutions (HEIs). Consequently, countries such as Uganda have lagged behind in promoting the attractiveness of their HEIs through such partnerships.

With the move towards knowledge-driven economies and societies, education has never been more important for the future economic standing of countries and individuals to perform and fully participate in the economy and society as it is today. ${ }^{2}$ The role of Ugandan universities has been perceived from the government point of view mostly as an instrument of economic development. Specifically, at Makerere there has been increasing awareness about the knowledge economy and the university's role as an engine of development. ${ }^{3}$

As a result of the value attached to $\mathrm{HE}$, there has been an exponential growth and expansion of HEIs in Uganda, as is the case the world over. However, this growth and expansion has not matched with the quality expected of HEIs, and has indeed posed challenges in the leadership and management of HEIs, especially in Sub-Saharan Africa ${ }^{4}$ and yet university leadership is one of the key actors in making a significant and sustained contribution to development. ${ }^{5}$

In Uganda, the growing number of HEIs, both public and private coupled with the declining quality of the graduates led to a recommendation for the

${ }^{1}$ Republic of Uganda, National Development Plan (2010); David Bloom et al., Higher Education (2006); Xiaoyan Liang, Uganda Tertiary (2004); Damtew Teferra and Philip Altbach, African Higher Education (2004); Republic of Uganda, Poverty Eradication Action Plan (1999).

${ }^{2}$ Organisation for Economic Co-operation and Development (OECD), Human capital (2007).

${ }^{3}$ Nico Cloete et al., Universities and economic development in Africa (2011), 154.

${ }^{4}$ Damtew Teferra and Philip Altbach, African Higher Education (2004); Peter Materu, Higher Education Quality (2007).

${ }^{5}$ Nico Cloete et al., (2011). 
establishment of a body to regulate quality of HEIs by the 1989 Education Commission. At the turn of the millennium, there were concerted efforts to improve quality in Uganda's HEIs. However, a decade later, a slower response in addressing the leadership and management challenges in HEIs has been noticeable ${ }^{6}$ implying that HE quality concerns have not been holistically addressed. Unfortunately, this development exemplifies the situation in many African countries. ${ }^{7}$

At international level, mass HE and knowledge growth have fundamentally altered the nature of university management structures, leading to the rise of the managerial approach in HE. ${ }^{8}$ The management of such huge organisations is complicated, i.e., '...too slow to respond, too unwieldy to direct, too focused on process rather than outcomes, and too short on professional expertise to guarantee quality, financial probity, and on-time delivery to multiple customers. ${ }^{9}$ Consequently, there is the dilemma of applying the traditional, widely accepted 'collegial' approaches to leading and managing $\mathrm{HE}$ in the institutional context, ${ }^{10}$ necessitating the adoption of New Public Management (NPM) approaches in the HE system. ${ }^{11}$ It is envisaged that these approaches positively impact the overall quality of HEIs.

Among the major arguments for the increased emphasis on quality assurance (QA) in HEIs include globalisation, internationalisation, new technologies, liberalisation of education, increased student enrolment, crossborder education due to demand for mobility of staff and students, market forces in HE delivery, changes in the relationship between governments and HEIs with more demand for control and accountability, and changes in funding patterns of HEIs by governments. ${ }^{12}$

${ }^{6}$ Proscovia Namubiru S. and Micheal Mawa, "Genesis of quality assurance in higher education institutions in Uganda" (unpublished, 2011).

7 Jamil Salmi, League Table (2007), 233; Demtew Teferra and Philip Altbach, African Higher Education (2004), 31.

${ }^{8}$ Paulo Santiago et al., Internationalisation (2008); Paul Ramsden, Leadership Challenge (1998)

9 Paul Ramsden, Leadership Challenge, 35.

${ }^{10}$ Paul Ramsden, Leadership Challenge.

${ }^{11}$ Lynn V. Meek, The Higher Education Managerial Revolution (2003)

12 Philip Altbach et al., Trends (2009); Uganda Government, White Paper on Education, (2008); Paulo Santiago et al., Internationalisation (2008); National Council for Higher Education (NCHE), Quality Assurance Framework (2006); Mahmoud Mamdani, Scholars in the Market Place (2007); National Council for Higher Education (NCHE), The State of Higher Education (2006); Nakanyike Musisi, Uganda (2003). 


\subsection{The policy context of HEIs in Uganda}

The evolution of QA in Africa in general, and in Uganda in particular is a response to global, regional and local developments. This is because African HE systems have become a part of global tuning, and through for instance the Africa-EU strategic partnership, efforts have been made towards the harmonisation of HE to enhance degree comparability, graduate mobility and employability in addition to improving staff capacity to design and develop curricula, provide opportunities for generation of additional resources, and supporting effective and productive networking. ${ }^{13}$

At national level, the QA system at Makerere University, the only university in Uganda by then (1949 to early 1990s), was based on institutional affiliation, external examination, moderation, and grading following the then University of London Model ${ }^{14}$ and later on with the collapse of the University of East Africa in 1970, a strong state control. In 1980, the Inter-University Council of East Africa (IUCEA) was formed, among others to regulate quality at the regional level. From the late 1980s, QA in HEIs was through external examination and moderation and evaluation of teaching staff by students. However, there was no national regulatory framework to coordinate QA in HIEs until 2001 when the Universities and Other Tertiary Institutions Act was promulgated.

With the promulgation of this Act, a national and institutional QA system gradually took form. This marked a move from affiliation to accreditation, collegial model to national benchmarks, and a strong mix of external and internal QA systems. ${ }^{15}$ With the establishment of the Uganda National Council for Higher Education (NCHE) the statutory regulatory authority for HE in Uganda, a National QA Framework was formulated to guide the QA system. The Framework defines QA as the mechanism put in place to guarantee that education is 'fit for purpose."16

The institutionalisation and operationalisation of the QA Framework in Uganda has taken two major directions. First, the traditional structures and mechanisms of institutional governance continue to play a dominant role in ensuring quality of the education provided. The management structures provide the legal and organisational framework within which administrative

13 Tuning Africa, http://www.tuningafrica.org/ .

${ }^{14}$ Peter Materu, Higher Education Quality (2007); Carol Sicherman, Becoming an African University (2005)

${ }_{15}$ Proscovia Namubiru and Michael Mawa, "Genesis of Quality Assurance" (unpublished, 2011).

${ }^{16}$ National Council for Higher Education (NCHE), Quality Assurance Framework (2006) 
decisions are made; they set the extent and limits of power of various players in the administration of the HEIs including councils, senate, academic boards, and students' and staff unions, among others. ${ }^{17}$ Therefore, the national and institutional frameworks provide a robust QA system through which Uganda HEIs are required to operate.

\subsection{Local framework for developing a quality programme}

Specific to academic programmes, the regulatory component of the National QA Framework mandates the Council to accredit individual institutions and programmes, while the institutional component stipulates that HEIs meet the requirements for courses of study and submit these to the NCHE for accreditation. The Council has published minimum standards for courses of study to measure the quality of academic programmes in terms of aims, learning outcomes, content, materials, delivery and assessment of students. The Council's minimum standards are the basis for academic programme accreditation in accordance with the Act which provides in section 119A that 'no person shall operate a University, other Degree Awarding or a Tertiary Institution without the prior accreditation of its academic and professional programmes by the National Council for Higher Education.' To establish whether or not an institution has complied with the requirements set by the QA Framework, a process of internal and external institutional and programme assessment or evaluation has been established. The Framework provides for a regular 3-5 year cycle of external audits; and as and when it is necessary to undertake such an audit. In addition, and relevant to this paper, the Framework requires a deliberate curriculum design and development process to ensure the quality of the academic programmes.

\subsection{Curriculum design, development and the changing product of knowledge}

In this paper, curriculum design is a deliberate process of devising, planning and selecting elements, techniques and procedures that constitute an organised learning endeavour. ${ }^{18}$ The design provides the conceptual framework within which a curriculum is developed.Curriculum development is the systematic planning of what is taught and learned in HEIs to bring

17 Abdu Kasozi, University education in Uganda (2003)

${ }^{18}$ Daniel Pratt, Curriculum design and development (1980), 10. 
about behaviour change among a specific group of learners. It involves the selection, organisation, execution and evaluation of the learning experiences on the basis of the needs, abilities, and interests of specific groups of learners, the mandate, vision and mission of the HEIs, the national legal frameworks and the needs and nature of the society. A curriculum development process that takes into consideration the above elements underscores a curriculum that is demand- rather than supply-driven.

Other scholars ${ }^{19}$ note two modes of knowledge production by which curriculum development can be defined. In Mode 1, production refers to knowledge of discipline-based type, typically produced in the 'traditional' universities. Mode 2 is the production of knowledge in the context of application, i.e. arising in the process of solving problems in collaborative trans-disciplinary teams and partnerships, situated both within and outside of HEIs. Similarly, the scope of Mode 2 of knowledge production has been expanded by emphasising the competence-based curriculum development process in HEIs. ${ }^{20}$ The curriculum designed and developed as analysed in this paper followed Mode 2 of curriculum development, in which generic competences and domain-specific competences related to the world of work, i.e. job profile are identified to guide the process.

Competence-based education is anchored in the learner-centred curriculum paradigm because of its emphasis on what the learner should be able to do when he or she is done with a particular training programme. In addition, competence-based education is also anchored in the problemcentred curriculum paradigm, since focus is on competences derived from societal needs and concerns, and since such a curriculum aims at preparing a graduate as an agent of social change. The problem-centred curriculum focuses on both generic and domain specific future professional practice of the graduate. The aim of the competence-based curriculum development process is to create a more relevant curriculum.

\subsection{Aim and objectives of the paper}

This paper aims at reflecting on and analysing the facilitators' experiences in migrating a professional $\mathrm{HE}$ curriculum based on a multi-institutional partnership in the curriculum design and development process. Specifically, the paper (1) analyses the process taken to design and develop the PGDHELM at UMI and (2) documents the lessons learnt during the development process.

${ }_{19}$ Michael Gibbons, et al., The new production of knowledge (1994).

${ }^{20}$ William Kouwenhoven, Designing for competence $(2003,2009)$. 


\subsection{Methodology}

The qualitative method of inquiry was adopted for this paper. The aim was to enable the facilitators understand and interpret the curriculum migration, redesign and development process as a social phenomenon within a HE setting from their own perspective and experience. Reflection as a research method is embedded within the wider action research frame of reference, ${ }^{21}$ which is intended to foster change on a group or institution. ${ }^{22}$ The research method was flexible, responsive and open to contextual interpretation drawing from the actual context. Reflections for the paper were drawn from all the workshops the facilitators participated in, with a total of 25 members of the curriculum task force. Data was mainly gathered through participant observations and documentation from the project document and workshop reports. All the steps in the workshops were noted. In addition, the facilitators also observed and documented the dynamics during the workshops. This paper presents a post-reflection process.

\section{Findings on the reflections}

\subsection{The curriculum design and development process}

The emphasis placed by NCHE for accreditation of all programmes offered by HEIs necessitates the development of programmes that meet the prescribed minimum standards for courses of study and respond to current needs in society. It is against this background and the need to address the governance challenges in Ugandan HEIs that UMI, in conjunction with Makerere University, the University of Helsinki and the University of Tampere embarked on migrating a professional programme on HE Administration, Leadership and Management taught at the University of Tampere to UMI in a multi-institutional partnership. This process gave birth to the Post-graduate Diploma in Higher Education Leadership and Management (PGDHELM). Certainly, even with such a donor-funded initiative and the active involvement of multi-institutional experts, UMI and its partners had to conform to the established national standards for programme accreditation.

Any good curriculum design and development process is based on an understanding of the educational philosophy and objectives of a particular

${ }^{21}$ Stephen Kemmis and Robin MacTaggart, The Action Research Planner (1988); Stringer, Action Research (1996).

${ }_{22}$ John Cunningham, Action Research and Organizational Development (1993). 
HEI, as well as the work-based knowledge and skills required for a given field. Specifically, the development of the competence-based PGDHELM programme can be described chronologically in the framework of a phased approach based on a combination of Hilda Taba's curriculum development model $^{23}$ and other best practices in curriculum design and development, including the following:

a) Conducting a needs assessment,

b) Designing the curriculum,

c) Aligning the curriculum to the mandate, vision, and mission of UMI,

d) Formulating the aim, competences and learning outcomes of the programme,

e) Selecting the content,

f) Selecting the learning experiences,

g) Organising the learning strategies and activities, and

h) Planning for assessment and programme review.

This paper restricted its scope to the planning elements in the curriculum development process, i.e. elements (a) to (g), because assessment and programme review takes place after the programme has been accredited and is operational. Elements (b) to (h) are the five mutually interactive elements of the curriculum development process, while elements (a) to (c) are considered factors external to Taba's model that affect the quality and relevance of a particular programme. The processes are reflected upon in the subsequent sections. However, the curriculum development process is iterative in nature; therefore, the phases reflected upon do not distinctly stand alone, but progress in a rather un-linear fashion.

\section{a) Conducting a needs assessment}

Although an often-neglected phase in curriculum design and development, conducting a needs assessment is a fundamental activity in which the curriculum development team scans the environment to identify the existing strengths and needs in terms of knowledge, skills and attitudes in society in regard to a particular field. This information is vital in identifying the knowledge, skills and attitudinal gaps that need to be addressed during the curriculum design and development process. In the process of developing the PGDHELM programme, relevant national and

\footnotetext{
${ }^{23}$ Hilda Taba, Curriculum development (1962).
} 
international literature was reviewed and a field study conducted among current and prospective HE managers and leaders. It was from this activity that the job profile of HE managers and leaders was developed, i.e. the generic and domain-specific competences of managers and leaders in HEIs in Uganda. The job profile further enabled the curriculum development team to describe the graduate profile of the prospective students and the curriculum profile.

Needs assessment in the curriculum design and development process attests to Mode 2 of knowledge production, ${ }^{24}$ i.e. the production of knowledge in the context of its application. This implies that the curriculum development team is aware of the importance of situating a training programme in the local and international context, in which the graduates are to work. Such a curriculum is secured in the requisite competences.

The involvement of stakeholders as important sources of power in the needs assessment and throughout the design and development process serves to co-opt, influence, and control the external environment. This is part of the politics in curriculum design and development, which enables an institution to seek and gain legitimacy through the creation of meaningful linkages and partnerships that consciously endorse the final curriculum. Such an environmental scan also gives a HEI the opportunity to seek a market for its service, i.e. clientele for its training programmes.

b) Curriculum design: Internationalising the PGDHELM programme through a multi-institutional partnership

Unique to the curriculum design and development process was the selection and active involvement of teaching staff from local HEIs, and a team of experts from two universities in Finland in the design and development of the PGDHELM programme. Guest speakers from local HEIs were also invited to give keynote addresses on identified thematic areas.

Specifically, and rather more uniquely, the programme was developed through a partnership under the project name: Building Institutional Capacity for Training Leadership and Management of Ugandan Universities (LMUU) with the University of Tampere, University of Helsinki, Makerere University and UMI as the partner institutions. The conception of this Project was a long-term commitment to institutional capacity building and cooperation between the Uganda Management Institute and Makerere University and the

${ }^{24}$ Michael Gibbons, Designing for competence (1998, cited in William Kouwenhoven, 2003, 1). 
University of Tampere. ${ }^{25}$ The LMUU Project therefore provided the programme a very unique and rich blend of international and local expertise, unlike many of the programmes developed in HEIs in Uganda.

A core team of 25 was purposely selected from Makerere University, the Uganda Ministry of Education and Sports and UMI to develop the training programme, which they would later on participate in facilitating after the accreditation process. This is in line with Taba $^{26}$ who argues that teachers who teach or implement the curriculum should participate in developing it. Taba calls this the grassroots approach. Closely related to Taba's model is curriculum design and development following the DACUM process, i.e. Developing A Curriculum. The DACUM process involves expert workers such as the core team of the 25 trainers in sharing what they do in their respective jobs and how they do it. Such information is used to design a DACUM chart, e.g. a job profile showing all the duties and tasks of a HE leader and manager. Through such a process, the locus in curriculum decision-making shifts from the top to the grassroots, thereby increasing the level of ownership and commitment of the curriculum team in the development process. As facilitators of the curriculum design and development process, we have found the DACUM process a cost-effective and time saving process.

During the curriculum design and development process, through a series of trainer of trainers' (TOT) workshops, the team of 25 shifted from being students on the Finnish Study Programme in Administration and Management of Higher Education (KOHA) hosted at the Higher Education Group, University of Tampere, to curriculum developers and finally to facilitators on the PGDHELM.

The migration process began with introducing the team of 25 to the KOHA Study Programme by the experts in HE educational management from the University of Tampere and University of Helsinki. The KOHA Programme provided the foundation for the core modules to be infused into the prospective Postgraduate Diploma in Higher Education Leadership and Management.

Figure one provides the model and a summary used to infuse components of the KOHA Programme into the prospective Postgraduate Diploma in Higher Education Leadership and Management. The model was adapted to capture the capacity building aspect of the project. ${ }^{27}$ There were two parallel

${ }^{25}$ Leadership \& Management of Ugandan Universities (LMUU) Project Completion Report (2012), 2.

${ }^{26}$ Hilda Taba, Curriculum development (1962).

${ }^{27}$ William Kouwenhoven, "Competence-based Curriculum Development in Higher Education: a Globalised Concept?", in Technology Education and Development, eds. Aleksandar Lazinica and Charles Calafate (2009). 
starting points for the curriculum development process, i.e. competent professional and the existing the KOHA Programme.

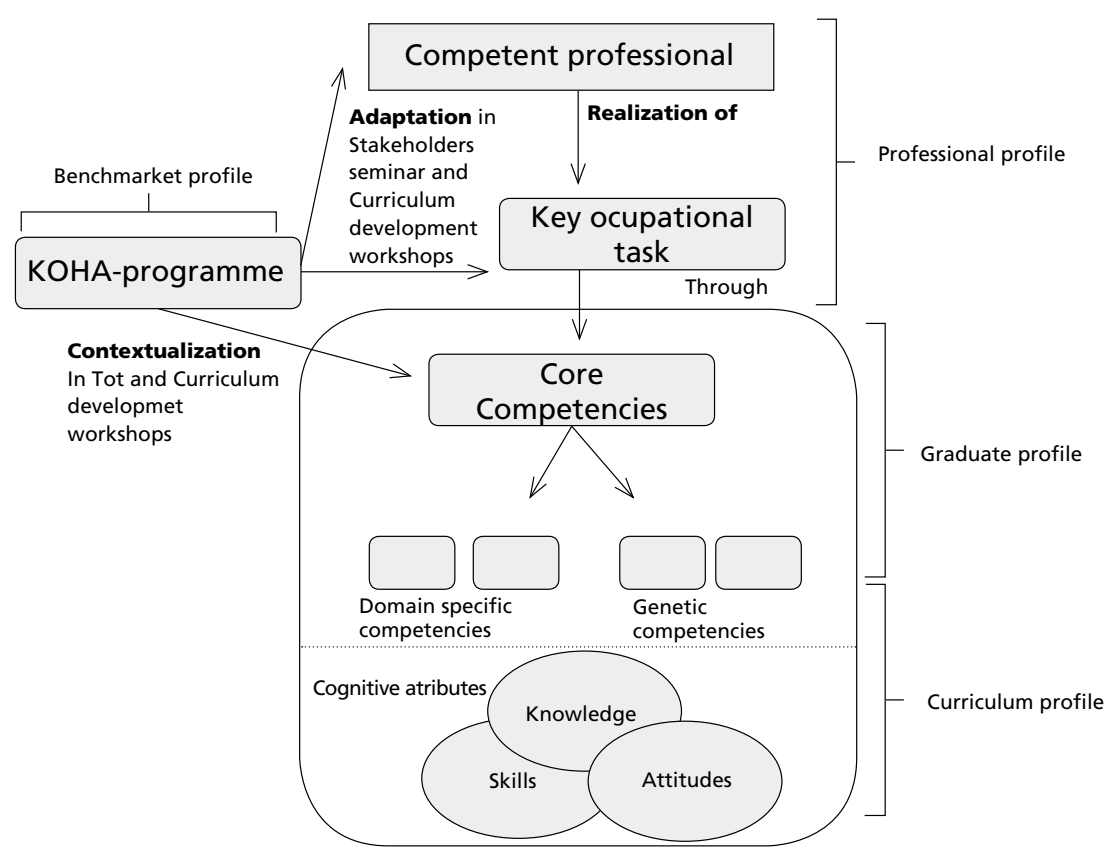

Figure 1

Migration of KOHA-programme as part of the competence based curriculum development. ${ }^{28}$

The introduction of the KOHA Programme was to acquaint the team with the content, enable them reflect on it in relation to the local context and subsequently re-orient the programme to suit the UMI context. The workshops, which were spread over six months, were facilitated by Finnish, African and Ugandan experts on key thematic areas in HE leadership and management. The core team was involved in reading the provided and other materials, doing research, group assignments and making presentations. This gave the team an international perspective and benchmark pertaining to leadership and management of HEIs. In addition, the group work enabled the

${ }^{28}$ Adopted from William Kouwenhoven, "Competence-based Curriculum Development in Higher Education: a Globalised Concept?", in Technology Education and Development (2009), 6 . 
team to collect information on the Uganda context. The knowledge and competences acquired, as well as the attitudes developed during the ToT workshops provided a basis for contextualising the prospective PGDHELM.

In addition, the competences on the KOHA programme were contextualised by the trained trainers to Ugandan circumstances. A competent professional for Ugandan HEIs was also defined. Further, the KOHA programme had an impact on the definition of a competent professional and his/her key occupational tasks which were defined in a stakeholder's workshop that had a wide participation from the Ugandan HEIs, the Ministry of Education and Sports, and other relevant agencies. The elaboration of the cognitive attributes was further done in detailed discussions during the TOT sessions and during the development of module handbooks. In addition, the trainers were exposed to the curriculum development process. Thereafter, new modules were developed and the content of existing modules upgraded.

As advocated by $\mathrm{Taba},{ }^{29}$ the formulation of a programme aim, competences and learning outcomes originates from a variety of sources e.g. societal demands, learners' needs and the subject disciplines. Using the KOHA Programme, the findings from the needs assessment and Blooms' Taxonomy of Educational Objectives guided the team to formulate several aim statements and jointly agree on a single programme aim. By the end of the ToT, the team had also developed very long lists of competences, which through a lengthy discussion process were categorized and from these categories, competences were developed. The competences were classified into six generic- and six domain-specific competences representing at least one of the programme modules. Thereafter, the selected competences were ranked in order of priority. These competences laid the foundation for the formulation of the programme learning outcomes, selection of the content, learning experiences and organizing the learning strategies and activities as provided for by Taba. ${ }^{30}$

The aim, competences and learning outcomes are key in programme alignment. They guide the selection of content, learning experiences, and the evaluation of learning outcomes. ${ }^{31}$ In addition, the statement of the programme aim, competences and learning outcomes enabled the curriculum development team to specify the explicit changes in behaviour the PGDHELM programme envisaged to bring about in the participants [read students] as a result of undertaking the training programme.

\footnotetext{
${ }^{29}$ Hilda Taba, Curriculum development (1962).

${ }^{30}$ Hilda Taba, Curriculum development (1962).

${ }^{31}$ Fred C. Lunenburg, "Curriculum development: Inductive models, in Schooling” (2011).
} 
This inter-institutional partnership is evident of the impact of internationalisation taking the form of a growing convergence of tertiary education systems and degree structures. ${ }^{32}$ The convergence of tertiary education programmes is also driven by the globalisation of professions, a trend yielding common concerns across countries regarding the performance of their tertiary education systems (TEIs). ${ }^{33}$ The development of the PGDHELM is a useful example of international networking and collaboration, the type described as involving intensive networking among institutions, scholars, and students, due to among others cross-border funding. ${ }^{34}$ It also presents a case of programme and staff mobility in an international context.

One of the forms of internationalisation identified by the literature is curriculum internationalisation focusing on programme content and delivery. This form consists of incorporating intercultural and international dimensions in the curriculum, teaching, research and extracurricular activities of TEIs to help students develop international and intercultural skills without ever leaving their country. ${ }^{35}$ From a policy perspective, this aspect is critical to develop internationally-competent citizens insofar as the overwhelming majority of tertiary students do not participate in more direct cross-cultural education experiences such as international mobility. ${ }^{36}$

Although internationalisation of HE curricula has been viewed negatively by some critics as a push towards a uniform market-driven curriculum, which would spread mono-cultural views as if they were universal ${ }^{37}$ a counter argument could be to consider curricula internationalisation from the perspective of benchmarking best practices, fostering student and staff mobility through the provision of attractive national $\mathrm{HE}$, as well as the opening up to international employment. The OECD Report ${ }^{38}$ also documents four rationales for growing internationalisation in tertiary education to include the mutual understanding approach between different nations and cultures; the revenuegenerating approach, the skilled migration approach and the capacity-building approach, which provide for further scrutiny in African HE.

32 Paulo Santiago et al., Internationalisation (2008).

${ }_{33}$ Paulo Santiago et al., Internationalisation (2008); David Woodhouse, 1999 cited in Santiago et al., Internationalisation (2008, 236).

${ }^{34}$ Paulo Santiago et al., Internationalisation, 15.

35 Organisation for Economic Co-operation and Development (OECD), (2004) cited in Santiago et al., Internationalisation, 240.

${ }^{36}$ Paulo Santiago et al., Internationlisation.

${ }^{37}$ Paul D. Ryan (2000), cited in Santiago et al., Internationalisation, 240; Parker and Jary (1995) cited in Santiago et al., Internationalisation, 240.

${ }_{38}$ Organisation for Economic Co-operation and Development (OECD), (2004) cited in Santiago et al., Internationalisation, 263. 
In this particular case, the 'infusion approach' ${ }^{39}$ was used to identify and infuse the internationally identified core competences of HE managers and leaders in the PGDHELM programme. Although internationalisation of HE curricula through infusion has been viewed negatively by some critics as exclusively building on western learning philosophy, emphasising summative learning outcomes, providing partial exposure to international and intercultural differences though passive class-based learning ${ }^{40}$ care was taken to align the PGDHELM programme to UMI's mandate, vision and mission, involve as many relevant stakeholders as possible, integrate local case studies and use local literature, as well as take the programme though the national accreditation process.

c) Formulating the PGDHELM programme aim, competences and learning outcomes

After the ToT, the facilitators organised a curriculum write-shop to give opportunity to the core team to develop the detailed programme. This included the refinement of the programme aim, competences and learning outcomes that had been previously developed, and the formulation of the same at module level. The five-day residential write-shop concluded with a draft Post Graduate Diploma in HE Leadership and Management aligned to the KOHA programme, UMI and NCHE requirements. The draft was further edited by a smaller team before submission to the School and Directorate Board of Studies at UMI.

The core team was divided into smaller module groups according to expertise to formulate the respective module aims and learning outcomes, cautious of the alignment between programme aim, competences and learning outcomes. Care was taken to have a balance in the representation of the cognitive, psychomotor and affective domains. The module aims, competences and learning outcomes provided the framework for selecting module content and learning experiences, organising learning activities and assessment strategies.

d) Selecting module content and learning experiences, organising learning strategies, assessment and programme review

Apart from programme review, which according to the National QA Framework (2006) occurs between 3-5 years after the programme has taken

39 Tonkin and Edwards (1981) cited in Santiago et al., Internationalisation, 240.

${ }^{40}$ De Vita and Case (2003) cited in Santiago et al., Internationalisation, 240. 
off, the selection of module content and learning experiences, and organisation of learning activities and assessment strategies was done concurrently during the five-day curriculum write-shop. Such a process has the advantage of taking into consideration constructive alignment of the key curricula elements ${ }^{41}$ than when each element is developed separately.

The smaller module expert groups developed the detailed draft modules using a prepared template that adheres to the minimum standards for courses of study provided by the NCHE and contextualised to UMI. The module expert groups developed among others the module rationale, description, aim, learning outcomes, detailed content, teaching and learning methods, assessment strategies, teaching and learning materials, and reading lists. Care was taken to align all the module elements to the programme aim, competences and learning outcomes. In selecting module content, attention was paid to the relevance, balance, validity, learnability, feasibility of the content with regard to the available resources and timetable provisions, among others.

In selecting the learning experiences at module level, appropriateness, feasibility, variety, and optimal value, were considered as key criteria. Thereafter, the team had a plenary session to review and critique the draft modules. Corrections were made there and then, and the draft PGDHELM programme was ready at the end of the write-shop. Among the advantages of using curriculum write-shops is that alignment is ensured right from the programme to individual module aim, competences, learning outcomes, objectives, content, teaching and learning methods and activities and assessment strategies. In addition, peer critique and support all through the writing process ensured rich curriculum content and adherence to the NCHE standards.

e) Aligning the programme to the mandate, vision and mission of UMI

The PGDHELM programme was developed taking into consideration the mandate, vision, mission and objectives of UMI. More specifically, the mandate of UMI is to conduct in-service training for public servants, and as 'Other Degree Awarding Institution' 42 to offer its own certificates, diplomas and degrees. Its vision is to be 'a World Class Management Development Institute' and mission 'to excel in developing sustainable management capacity. ${ }^{43}$

${ }^{41}$ John Biggs, Teaching for quality learning at university (2003).

${ }^{42}$ UOTIA - Universities and Other Tertiary Institutions Act (2006, amended).

${ }^{43}$ Uganda Management Institute (UMI), "Strategic Plan" (2013). 
UMI's mandate, vision, and mission served as the framework within which the PGDHELM programme was designed and developed, which further served to institutionalise an international field of study. The Institutes' mandate, vision, and mission provided the internal standards for the quality of the programme in terms of policies and procedures including students' selection and admission criteria, quality of academic staff, programme structure, delivery, assessment and examination strategies, graduation load, infrastructure, facilities, and timetabling. For instance, modules that are basic to all UMI postgraduate programmes were blended into the programme.

The alignment of training programmes to the mandate, vision, and mission is part of internal self-regulation, since a HEI seeks to respond to its own internal standards. This is in line with the institutional theory, which propounds that institutions react to change in line with their profiles, missions and visions and reorganize their inner structures as a survival measure. ${ }^{44}$ However, in acquiescing as an institutional strategy, the institution first and foremost conforms to the internal standards and measures before they can confirm to the external environment, i.e. the external QA requirements.

Alignment of programmes with the institutional mandate, vision and mission is a sine qua non as a matter of effective management. ${ }^{45}$ Such alignment is a response to the internal consistency of a training programme, or fitness of purpose, a measure of internal quality. In such instance, the curriculum design and development team is cognizant of the need to respond to the institutional mission, related strategic choices, priorities and principles, to retain its own identity, and answer to its own principles. ${ }^{46}$ Elsewhere, literature documents the importance of HEIs to demonstrate a high level of QA in the context of their missions and visions. ${ }^{47}$ The more the internal stakeholders notice a familiar pattern of the new curriculum to existing curricula, the more the ownership of such a curriculum is strengthened. The authors of the current paper refer to such a process as curriculum patterning or modeling. Curriculum patterning or modeling is manifested in various ways including in the design and development process itself, the external and internal structure of the curriculum, language used, among others.

${ }^{44}$ Richard Scott, Institutions and organizations (1995).

${ }^{45}$ LH Martin/INQAAHE, External quality assurance (2012).

${ }^{46}$ Ibid.

${ }^{47}$ Bente Kristensen, External quality assurance (2010); Middles States Commission on Higher Education, Characteristics of excellence (2006); Commonwealth of Australian, Australian higher education quality assurance (2000). 
In addition, the internal QA standards were carefully aligned to the provisions in the National QA Framework (2006), since the Framework requires individual accreditation of academic programmes. Below is the summary of the internal QA processes undertaken in the development of training programmes in HEIs in Uganda, and with particular reference to UMI:

a) Undertaking a needs assessment to identify current strengths and gaps in a particular field of study at local, regional and international levels. This is initiated at departmental level. The findings from the needs assessment support the Department in coming up with a strong justification when drafting the proposed training programme.

b) Presentation of the draft proposed training programme to the Departmental Board of Studies for discussion.

c) Submission of the draft proposal to the respective School for discussion.

d) Organisation of a stakeholders' workshop by the respective School for further input.

e) Submission of the revised proposal to the Directorate Board of Studies.

f) Submission of the revised proposal to the Quality Assurance Unit.

g) Submission of revised proposal to Senate.

h) Submission of the final proposal to National Council for Higher Education for accreditation. ${ }^{48}$

Key in the process was the involvement of both internal and external stakeholders during needs assessment, as well as in the design and development process. For instance, during the needs assessment, the stakeholders identified the current strengths, gaps and competences needed in the leadership and management of HEIs in Uganda. Among the internal stakeholders was a smaller team that constituted the curriculum task team in designing and developing the PGDHELM programme. The team members were teaching staff, and either current or prospective HE leaders and managers. Participation of staff in the design and development process is a motivating factor, which propels professional growth and development, as well as ownership and responsibility in the curriculum implementation and review processes. Indeed, their participation provided them the opportunity to gain deeper understanding of the contemporary challenges and needs of leaders and managers in HEIs.

${ }^{48}$ Uganda Management Institute (UMI), “Quality Assurance Guidelines” (2010). 


\section{f) ToT workshop}

The concluding phase in the curriculum design and development process after the PGDHELM programme was accredited by NCHE was holding a ToT for the facilitating team in preparation for full programme implementation. This phase, although not considered by $\mathrm{Taba}^{49}$ was fundamental in re-skilling the selected team of facilitators with the requisite competences in delivery of the programme. Using a predefined peer assessment sheet, the facilitators were reviewed by their peers as they practiced team teaching using sessions of their choice extracted from the modules.

\section{Lessons learnt}

The opportunities opened up for north-south and south-south partnerships in curriculum design and development are positive responses to internationalisation of HE. Partnerships and collaborations among HEIs in the joint design, development, implementation and review of HEIs programmes is key in capacity building, expanding the repertoire of knowledge, skills, and attitudes in building stronger networks. Such forums provide platforms for learning and support through information-sharing. However, this may in future necessitate the harmonisation of qualifications and awards to ease curriculum, student and staff mobility.

Training programmes that stand the test of time are those in which stakeholders are actively involved in their development, implementation and review. This not only emphasises quality, but also relevance of the programmes. The relevance of training programmes migrated from another setting is further enhanced through observance of the national and institutional regulations. This is likely to lead to program sustainability.

HEIs in Uganda are gradually moving away from the development of discipline-based knowledge curricula, typically produced in the 'classical' universities to the production of knowledge in the context of application, i.e. arising in the process of solving problems in collaborative trans-disciplinary teams and partnerships, situated both within and outside the HEIs. Using the DACUM approach as a basis for competence-based curriculum development, HEIs curriculum development teams engage in backwards curriculum development beginning with the identification of generic competences and domain-specific competences related to the world of work. Competences are

\footnotetext{
${ }^{49}$ Hilda Taba, Curriculum development (1962).
} 
increasingly considered effective in guiding the curriculum design and development process.

Curriculum development is not a linear process, it involves a forward and backward movement as the developers negotiate, renegotiate and make decisions. Closely related to the above, curriculum development is a political process, reflecting the identity, assumptions, and perspectives of individuals, groups and institutions. According to Goodson, ${ }^{50}$ curriculum practice 'is a multifaceted concept, constructed, negotiated, and renegotiated at a variety of levels and in a variety of arenas.' Although it is not always easy to incorporate the multiple perspectives of such groups, the way these aspects are handled in the process influences the subsequent phases of development, implementation and review.

Curriculum development is an expensive venture requiring institutional commitment in terms of logistical support, or else even with the most seasoned team of curriculum developers, the process will be rushed and the output shoddy.

The curriculum development process challenged the basic problem of applying a European professional curriculum to an African HE setting and within a national quality assurance framework in a short project period of 1.5 years. The most important lesson learnt was the importance of parallel contextualisation and training of trainers that ensured three things. First it made possible to utilise the existing (Finnish) knowledge. Second, it enabled the fast start of the project. Thirdly, and most importantly, through the stakeholder seminars it ensured that the graduate profile was adapted to the Ugandan context and that the knowledge was contextualised to African circumstances.

\section{Conclusion}

The curriculum migration process provided an opportunity to collaborate and network in a way that may have never been experienced before in HEIs in Uganda. Normal practice in HIEs in Uganda is that either individuals or groups of experts at departmental level write programmes, present them in their respective departments, Schools, Directorate and finally Senate before they are submitted to the NCHE. At UMI, before programmes are presented at Directorate level, a half-day workshop is organised to allow stakeholders to review and give their input to the draft programmes.

${ }^{50}$ Ivor F. Goodson, Studying curriculum (1991), 49. 
This rigorous process provides useful checks and balances during the curriculum design and development process, makes the process flexible and open, ensures responsiveness of HEIs to the graduate labour market outcomes $^{51}$, brings in a rich blend of knowledge, skills and attitudes due to the involvement of various stakeholders, and allows ownership and sustainability of the programme. The challenge is the lengthy process before the proposed programme is submitted to NCHE for accreditation. The process may span between six months to one year, or more. By the time the programme is accredited, it is almost two years old, due for another review cognizant of the increasingly knowledge-driven global economy.

Future trends point towards a more harmonised QA system in HEIs as taking precedence over many university preoccupations, especially with the strengthening of national, regional and international HE systems, international twinning and networking schemes in HEIs, the mobility of HEIs, programmes, students and staff, and increased institutional selfassessment and auditing.

Due to the liberalisation of the economy, there is a perception that HEIs are for-profit. Even those that are public such as Makerere University run parallel privately sponsored programmes as income generating projects amidst dwindling government financial support. Because of this negative competitive element in HEIs, universities are still lax establishing twinning and networking programmes to collaborate at national and regional levels. One of the success stories has been the collaboration between University of Helsinki, University of Tampere, Makerere University and UMI that saw a successful joint development of the Postgraduate Diploma in Higher Education Leadership and Management currently in its first year of inception at UMI at the time of writing this paper.

\section{Bibliography}

Altbach, G. Philip, Liz Reisberg, and Laura E. Rumbley. "Trends in global higher education: Tracking an academic revolution." A report prepared for the UNESCO 2009 World Conference on Higher Education, Paris, UNESCO, 2009.

Biggs, John. Teaching for quality learning at university. The Society for Research into Higher Education and Open University Press, Buckingham, 2003.

Bloom David, David Canning, and Kevin Chan. Higher Education and Economic Development in Africa. Harvard University, A research commissioned by the World Bank - AFTHD, 2005.

${ }^{51}$ Paul Santiago et al., Internationlisation (2008). 
Cloete Nico, Tracy Bailey, Pundy Pillay, Ian Bunting, and Peter Maasen. Universities and economic development in Africa. Centre for Higher Education Transformation (CHET), South Africa: Wynberg, 2011.

Commonwealth of Australia. "The Australian higher education quality assurance framework." Occasional Paper Series. Australia: Higher Education Division Department of Education, Training and Youth Affairs, 2000.

Cunningham, B. John. Action Research and Organizational Development. Westport, CT: Preager Publishers, 1993.

Gibbons, Michael, Camille Limoges, Helga Nowotny, Simon Schwartzman, Peter Scott and Martin Trow. The new production of knowledge: The dynamics of Science and Research in contemporary societies. London: Sage Publication, 1994.

Goodson, F. Ivor. "Studying curriculum: Towards a social constructionist perspective." In Qualitative educational research studies: Methodologies in transition, eds. Ivor F. Goodson and M. Mangan, 49-90. Research Unit on Classroom Learning and Computer Use in Schools. London, ON: Faculty of Education, The University of Western Ontario.

Government of Uganda. Universities and Other Tertiary Institutions Act, Supplement No.6. Entebbe: UPPC, 2001.

Harvey Lee and Bjørn Stensaker. "Quality Culture: understandings, boundaries and linkages.” European Journal of Education 43, nº (2008): 427- 442.

- and John Williams. "Fifteen years of Quality in Higher Education." Special Issue Quality in Higher Education 16, n 1(2010): 3 - 36.

Kasozi, B. K. Abdul. University Education in Uganda: Challenges and opportunities for reform. Kampala: Fountain Publishers, 2003.

Kemmis Stephen, and Robin McTaggart. The Action Research Planner. Geelong: Deaking University Press, 1988.

Kouwenhoven, William. "Competence-based Curriculum Development in Higher Education: a Globalised Concept?" In Technology Education and Development, eds. Aleksandar Lazinica and Charles Calafate, 2009. Accessed June, 2013 from http://www.intechopen.com/books/technology-education-and-development/ competence-based-curriculum-development-in-higher-education-a-globalconcept-.

— .Designing for competence: Towards a competence-based curriculum for the faculty of education of the Eduardo Mondlane University." Doctoral Dissertation, Twente University (90 3651985 3, Enschede), 2003.

Kristensen, Bente. "Has external quality assurance actually improved quality in higher education over the course of 20 years of the 'Quality Revolution'?" Quality in Higher Education 6, $\mathrm{n}^{\circ} 2$ (2010).

Leadership and Management of Ugandan Universities (LMUU). "Project Completion Unpublished Report.” 2012.

LH Martin Institute/INQAAHE. "External quality assurance: Quality Assurance for higher education, establishing a QA system- the choices." Unpublished lecture notes, Graduate Certificate in Quality Assurance, University of Melbourne/ LH Martin Institute, 2012. 
Liang, Xiaoyan. Uganda Tertiary Education Sector, Africa Region Human Resource Development. Working Paper Series: Washington, D.C.: World Bank (Africa Region Human Development Department), 2004.

Lunenburg, C. Fred. "Curriculum development: Inductive models." Schooling $2 \mathrm{n}^{\circ} 1$ (2011). Accessed June, 2013 http://www.nationalforum.com/ ElectronicJounral Volumes/Lunenburg,\&FredCurri

Mamdani, Mahmoud. Scholars in the Marketplace: the dilemmas of neo-liberal reform at Makerere University, 1989-2005. Kampala: Fountain Publishers, 2007.

Materu, Peter. Higher Education Quality Assurance in Sub-Saharan Africa: Status, Challenges, Opportunities and Promising Practices. World Bank Working Paper, No. 124. Washington, D.C.: World Bank (Africa Region Human Development Department), 2007.

Meek, V. Lynn. Introduction to The Higher Education Managerial Revolution, eds. Alberto Amaral, Lynn V. Meek and Ingvild M. Larsen, 1-29. Dordrecht: Kluwer, 2003.

Middle States Commission on Higher Education. "Characteristics of excellence in higher education." Philadelphia, PA: Middle States Commission on Higher Education, 2006.

Nakanyike, B. Musisi. "Uganda." In African higher education: An international reference handbook, edited by Damtew Teferra and Philip G. Altbach, 611-623 Bloomington and Indianapolis: Indiana University Press, 2003.

Namubiru S. Proscovia, and Mawa Micheal. "The Genesis of Quality Assurance Systems in Higher Education Institutions in Uganda." Paper presented at the Annual Southern African Comparative and History of Education Society Conference at Speak Resort, Munyonyo, Kampala, Uganda, $8^{\text {th }}$ August, 2011.

National Council for Higher Education (NCHE). Quality Assurance Framework for Universities. Kampala: NCHE, 2006.

- The State of Higher Education and Training in Uganda: A report on higher education delivery and institutions. Kampala: NCHE, 2006.

Oliver, Christine. "Strategic responses to institutional processes." Academy of Management Review 16, nº 1 (1991): 145-179.

Organisation for Economic Co-operation and Development (OECD). Human capital: How what you know shapes your life. Paris: OECD Publishing, 2007.

Pratt, Daniel. Curriculum design and development. New York: Harcourt Brace Jovanovich, 1980.

Ramsden, Paul. The leadership challenge in the contemporary context of higher education: Learning to lead in higher education. Routledge, London, 1998:12-17.

Republic of Uganda. "National Development Plan 2010/11 - 2014/15." Kampala: National Planning Authority, 2010.

- "Poverty Eradication Action Plan: A National Challenge for Uganda. Vol. 1.”Kampala: Ministry of Finance, Planning and Economic Development, 1999.

- "Uganda Government White Paper on Education Report on the Visitation Committee to Public Universities in Uganda." Kampala: Ministry of Education and Sports, 2008. 
Rhoades, Gary, and Barbra Sporn. "Quality Assurance in Europe and US: Professional and political economic framing of higher education policy." Higher Education 43 (2002): 355 - 390 .

Saint, William. "Higher Education in Ethiopia: The Vision and Its Challenges." JHEA/RESA 2, no 3 (2004): 83-113.

Salmi, Jamil. "League Tables as Policy Instruments: Uses and Misuses.” Journal of the Programme on Institutional Management in Higher Education Management and Policy19, n 2 (2007).

Santiago Paulo, Karine Tremblay, Ester Basri, and Elena Arnal. "Internationalization: Shaping strategies in the national context." In Tertiary Education for the Knowledge Society Volume 1, edited by OECD Paris: OECD, 2008.

Scott, W. Richard. Institutions and Organizations .Thousand Oaks: Sage, 1995.

Sicherman, Carol. Becoming an African University: Makerere 1922-2000. Kampala: Fountain Publishers, 2005.

Ssekamwa, C. John. History and Development of Education in Uganda. Kampala: Fountain Publishers, 1997.

Stringer, T. Ernest. Action Research. A Handbook for Practitioners .London: Sage Publications, 1996.

Taba, Hilda. Curriculum development: Theory and practice .New York: Harcourt Brace, 1962.

Teferra, Damtew, and Philips G. Altbach. "African higher education: Challenges for the 21st century." Higher Education 47 (2004): 21-50.

Tuning Africa. http://www.tuningafrica.org/ Accessed on the $27^{\text {th }}$ of Nov., 2013.

Uganda Management Institute (UMI). "Postgraduate Diploma in Higher Education Leadership and Management (PDGHELM)". Kampala: Uganda Management Institute, 2012.

_ "Quality Assurance Guidelines.” Place of publication: Uganda Management Institute, 2010.

—. "Strategic Plan 2013-2017." Uganda Management Institute, 2013. 